\title{
Stochastic Growth in the United States and Euro Area
}

\author{
Peter N. Ireland* \\ Boston College and NBER
}

August 2010

\begin{abstract}
This paper estimates, using data from the United States and Euro Area, a two-country stochastic growth model in which both neutral and investment-specific technology shocks are nonstationary but cointegrated across economies. The results point to large and persistent swings in productivity, both favorable and adverse, originating in the US but not transmitted to the EA. More specifically, the results suggest that while the EA missed out on the period of rapid investment-specific technological change enjoyed in the US during the 1990s, it also escaped the stagnation in neutral technological progress that plagued the US in the 1970s.

JEL: E32, F41, F43, O41, O47.
\end{abstract}

*Please address correspondence to: Peter N. Ireland, Boston College, Department of Economics, 140 Commonwealth Avenue, Chestnut Hill, MA 02467-3859. Tel: (617) 552-3687. Fax: (617) 552-2308. Email: irelandp@bc.edu. http://www2.bc.edu/ irelandp. I would like to thank Fabio Canova and three anonymous referees for extremely helpful comments and suggestions. The opinions, findings, conclusions, and recommendations expressed herein are my own and do not reflect those of the National Bureau of Economic Research. 


\section{Introduction}

For more than two centuries, the United States and Europe have been linked economically, through international trade in goods and services and two-way flows of technical and scientific knowledge. Now, following European monetary unification, the US and Euro Area stand among the world's largest economies, roughly equal in population and productive capacity. Still, even over periods as long as decades, key aggregate variables can behave quite differently across the US and EA.

For instance, the top panel of figure 1 plots the natural logarithms of real consumption and investment in the US (the appendix describes in more detail these and all other data used in this study). The graph normalizes the level of each series to zero in 1970 so as to highlight one of the most remarkable developments in recent macroeconomic history: the growth of US investment that has far outstripped growth in consumption, especially since 1990. Greenwood, Hercowitz, and Krusell (1997) interpret this aspect of the US data as part of a larger body of evidence pointing towards the importance of investment-specific, or capital-embodied, technological progress, thereby offering up an alternative explanation for the long-run growth of the US economy that contrasts with the traditional view, going back to Solow (1957), that emphasizes neutral, or disembodied, technological change instead. Likewise, Fisher (2006) argues that investment-specific technology shocks are more important in accounting for US output and employment fluctuations than the neutral technology shocks that appear in standard real business cycle models starting with Kydland and Prescott's (1982).

But, as the bottom panel of figure 1 reveals, the same rapid growth in investment simply fails to appear in data from the EA. To an extent, some of this difference may be due to errors in measurement, since the US National Income and Product Accounts are generally believed to do a better job than the Euro Area statistics aggregated by Fagan, Henry, and Mestre (2005) at accounting for quality change in capital goods. However, Sakellaris and Vijselaar (2005) present results of detailed calculations that suggest that when similar adjustments for quality improvements are made to data from both economies, the differences not only remain, but may become larger still. Furthermore, the comparisons drawn in figure 1 are striking because they show that while the US and 
EA have both experienced extended departures from the type of balanced growth that appears in the traditional one-sector stochastic growth model studied by King, Plosser, Stock, and Watson (1991), these departures have taken the two economies in totally different directions: in the US, real investment has grown faster than consumption, whereas in the EA, exactly the opposite has been true.

In any case, the analysis in this paper takes the data from figure 1 at face value, while awaiting improvements in the collection, adjustment, and presentation of those data by national and international authorities, and interprets them using a two-country dynamic, stochastic, general equilibrium model like that first developed by Backus, Kehoe, and Kydland (1994). Here, in particular, Backus, Kehoe, and Kydland's international real business cycle model is converted into what might more accurately be called a two-country stochastic growth model by allowing, within the context of that model, for highly persistent movements in the rates of both neutral and investment-specific technological change that can explain the departures from balanced growth exhibited in figure 1. This two-country model is then estimated via maximum likelihood using data from both economies; the estimated model works, quantitatively, to break the differential action in those data into components attributable to both types of productivity growth. The results of this empirical exercise confirm that the Euro Area missed out on the period of rapid investment-specific technological change enjoyed by the US during the 1990s. But they also reveal that the EA escaped the stagnation in neutral technological progress that appears responsible for the US productivity slowdown of the 1970s. More generally, the results point repeatedly to large and persistent swings, both favorable and unfavorable, in both types of technological progress experienced in the US but not transmitted to the EA.

By examining the data with the help of a fully-specified and tightly-parameterized dynamic, stochastic, general equilibrium model, the empirical analysis conducted here can look beyond the time series that are used to estimate the rates of neutral and investment-specific technological change and consider the quantitative implications of those productivity trends for other key macroeconomic variables as well. In particular, the estimated model is also used below to explore 
the links between macroeconomic quantities like real consumption and investment and macroeconomic prices like the real exchange rate and the relative price of investment goods. By comparing the model's implications along these extra dimensions to additional data, this study relates to and extends a body of other recent work that attempts to account for the joint dynamics of aggregate quantities and prices using calibrated or estimated DSGE models of closed and open economies. But, to begin, the next section presents the model itself.

\section{A Two-Country Stochastic Growth Model}

\subsection{Overview}

The basic elements of this two-country model are drawn from Backus, Kehoe, and Kydland's (1994) framework, modified by replacing their assumption of complete international capital markets with Heathcote and Perri's (2002) alternative that only a single, non-contingent bond gets traded across economies. In addition, investment-specific technology shocks get introduced as in recent work by Raffo (2009), and both neutral and investment-specific technology shocks are assumed to be nonstationary but cointegrated across countries, borrowing a key element from Rabanal, Rubio-Ramirez, and Tuesta's (2009) specification. As noted above, these various modifications and extensions turn Backus, Kehoe, and Kydland's international real business cycle model into a two-country stochastic growth model that can account for the persistent departures from balanced growth shown in figure 1 but, at the same time, also admits that flows of scientific and technological knowledge ought, in the very long run at least, to equalize the levels of productivity across the US and EA.

In all that follows, home (US) and foreign (EA) variables are denoted with $H$ and $F$ superscripts, time periods with $t=0,1,2, \ldots$ subscripts. Each economy has a representative consumer, a representative intermediate goods-producing firm, a representative final goods-producing firm, and a government, whose activities will now be described in turn. 


\subsection{Consumers}

The representative home consumer has preferences described by the expected utility function

$$
E_{0} \sum_{t=0}^{\infty} \beta^{t}\left\{\frac{\left[\left(C_{t}^{H}\right)^{\mu}\left(1-L_{t}^{H} / M_{t}^{H}\right)^{1-\mu}\right]^{1-\gamma}-1}{1-\gamma}\right\}
$$

where $C_{t}^{H}$ and $L_{t}^{H}$ denote consumption and hours worked, the discount factor $\beta$ and the consumptionversus-leisure share parameter $\mu$ lie between zero and one, and the risk aversion coefficient $\gamma$ is strictly positive. The preference shock $M_{t}^{H}$ impacts on the marginal rate of substitution between consumption and leisure in a way that associates positive innovations with increases in equilibrium employment. Hall (1997), Mulligan (2002), Chang, Doh, and Schorfheide (2007), Kahn and Rich (2007), and Ireland and Schuh (2008) also consider preference shocks of this kind, emphasizing that they can stand in for a wide variety of nontechnological disturbances that potentially play a role in driving aggregate fluctuations. Here, these shocks are introduced in a similar spirit, as an additional source of dynamics, so that the estimated model is not forced from the start to attribute all or even most of the action found in the data to the various technology shocks. Below, two extensions of Chang, Doh, and Schorfheide's (2007) specifications are considered: one in which the preference shocks in both countries are persistent but stationary and the other in which the preference shocks are nonstationary but cointegrated across countries.

For convenience, all prices in both countries are expressed in terms of a common, abstract unit of account. Accordingly, let $W_{t}^{H}$ denote the domestic nominal wage, $Q_{t}^{H}$ the domestic nominal rental rate for capital, $P_{t}^{H}$ the nominal price of the home consumption good, $X_{t}^{H}$ the nominal price of the home investment good, and $1 / R_{t}$ the price at time $t$ in units of the home consumption good of a real bond that returns one unit of the home consumption good at time $t+1$. Let $K_{t}^{H}$ denote the domestic consumer's holdings of physical capital at the beginning of period $t, D_{t}^{H}$ the number of bonds carried by the domestic consumer from period $t-1$ into period $t$, and $T_{t}^{H}$ lump-sum taxes, expressed in nominal terms, paid by the domestic consumer to the domestic government during 
period $t$. Then the consumer's budget constraint can be written in real terms as

$$
\begin{aligned}
\frac{W_{t}^{H} L_{t}^{H}+Q_{t}^{H} K_{t}^{H}}{P_{t}^{H}}+D_{t}^{H} \geq & C_{t}^{H}+\frac{X_{t}^{H} I_{t}^{H}+T_{t}^{H}}{P_{t}^{H}}+\frac{D_{t+1}^{H}}{R_{t}} \\
& +\left(\frac{\phi_{d}}{2}\right) U_{t}^{H}\left(\frac{D_{t+1}^{H}}{U_{t}^{H}}\right)^{2}+\left(\frac{\phi_{l}}{2}\right) U_{t-1}^{H}\left(\frac{L_{t}^{H}}{L_{t-1}^{H}}-1\right)^{2} L_{t-1}^{H}
\end{aligned}
$$

for the model with stationary preference shocks and

$$
\begin{aligned}
\frac{W_{t}^{H} L_{t}^{H}+Q_{t}^{H} K_{t}^{H}}{P_{t}^{H}}+D_{t}^{H} \geq & C_{t}^{H}+\frac{X_{t}^{H} I_{t}^{H}+T_{t}^{H}}{P_{t}^{H}}+\frac{D_{t+1}^{H}}{R_{t}} \\
& +\left(\frac{\phi_{d}}{2}\right) U_{t}^{H}\left(\frac{D_{t+1}^{H}}{U_{t}^{H}}\right)^{2}+\left(\frac{\phi_{l}}{2}\right) U_{t-1}^{H}\left(\frac{L_{t}^{H}}{L_{t-1}^{H}}-m\right)^{2}\left(\frac{L_{t-1}^{H}}{M_{t-1}^{H}}\right) .
\end{aligned}
$$

for the model with nonstationary preference shocks.

As discussed by Schmitt-Grohe and Uribe (2003) for the case of a small open economy, the second-to-last term on the right-hand side of (2) and (3) introduces arbitrarily small costs of bond purchase or issuance, measured in units of the consumption good, that guarantee that a suitablytransformed set of conditions describing the model's equilibrium has a unique stationary solution. Meanwhile, the last terms in (2) and (3) introduce adjustment costs for hours worked, following Ireland and Schuh (2008), that slow down and smooth out the response of home employment to both domestic and foreign disturbances; Chang, Doh, and Schorfheide (2007) also find that labor adjustment costs of this kind matter when assessing the importance of persistent preference shocks like those considered here. The form of the labor adjustment cost must vary across (2) and (3) to reflect the fact that in the model with nonstationary preference shocks, hours worked $L_{t}^{H}$ inherits a stochastic trend from the preference shock $M_{t}^{H}$ and therefore grows in the long run at the same gross rate $m$ as the preference shock itself. Also, as in Rabanal, Rubio-Ramirez, and Tuesta (2009), both adjustment cost terms must be scaled by a factor $U_{t}^{H}$, equal to $\left(V_{t}^{H}\right)^{\alpha /(1-\alpha)} Z_{t}^{H}$ for the model with stationary preference shocks and $M_{t}^{H}\left(V_{t}^{H}\right)^{\alpha /(1-\alpha)} Z_{t}^{H}$ for the model with nonstationary preference shocks, where $Z_{t}^{H}$ is the home neutral technology shock, $V_{t}^{H}$ is the home investmentspecific technology shock, and the parameter $\alpha$ measures capital's share in production, so that 
these costs expand in line with the overall economy in this model with long-run growth. The bond adjustment cost parameter $\phi_{d}$ must be strictly positive for the model to have a unique steady-state growth path, the labor adjustment cost parameter $\phi_{l}$ is nonnegative, and the form of both adjustment cost specifications is such that the level of these costs is zero along the steady-state growth path.

By purchasing $I_{t}^{H}$ units of the domestic investment good during period $t$, the consumer increases the stock of capital available in the home country between $t$ and $t+1$ according to

$$
(1-\delta) K_{t}^{H}+I_{t}^{H}-\left(\frac{\phi_{k}}{2}\right)\left(\frac{I_{t}^{H}}{K_{t}^{H}}-\eta^{H}\right)^{2} K_{t}^{H} \geq K_{t+1}^{H}
$$

where the depreciation rate $\delta$ lies between zero and one. The last term on the left-hand side of (4) introduces capital adjustment costs, common to most international real business cycle models, that slow down and smooth out the response of home investment to both domestic and foreign shocks. The capital adjustment cost parameter $\phi_{k}$ is nonnegative, and a value for the positive parameter $\eta^{H}$ will be set later on to equal the constant ratio of investment to capital in the home country along the steady-state growth path, so that the level of these costs again equals zero along that path.

Hence, the representative home consumer chooses $C_{t}^{H}, L_{t}^{H}, I_{t}^{H}, K_{t+1}^{H}$, and $D_{t+1}^{H}$ for all $t=$ $0,1,2, \ldots$ to maximize the utility function (1) subject to the budget constraint (2) or (3) and the capital accumulation constraint (4), both of which must hold for all $t=0,1,2, \ldots$. The representative foreign consumer solves a symmetric problem, involving the choice of foreign consumption $C_{t}^{F}$, hours worked $L_{t}^{F}$, investment $I_{t}^{F}$, and holdings of capital $K_{t+1}^{F}$ and bonds $D_{t+1}^{F}$ for all $t=0,1,2, \ldots$ to maximize a utility function having the same form as (1) but which gets hit by the foreign preference shock $M_{t}^{F}$, subject to constraints that parallel (2) or (3) and (4) for all $t=0,1,2, \ldots$.

\subsection{Intermediate Goods-Producing Firms}

The representative home intermediate goods-producing firm rents $K_{t}^{H}$ units of capital and hires $L_{t}^{H}$ units of labor to produce $Y_{t}^{A}$ units of an internationally-traded intermediate good according to the 
Cobb-Douglas specification

$$
\left(K_{t}^{H}\right)^{\alpha}\left(Z_{t}^{H} L_{t}^{H}\right)^{1-\alpha} \geq Y_{t}^{A}
$$

where the share parameter $\alpha$ lies between zero and one and, as noted above, $Z_{t}^{H}$ denotes the neutral technology shock experienced in the home country. The firm sells its output domestically and abroad at the common price $P_{t}^{A}$; during each period $t=0,1,2, \ldots$, it chooses $Y_{t}^{A}, K_{t}^{H}$, and $L_{t}^{H}$ in order to maximize its profits, $P_{t}^{A} Y_{t}^{A}-Q_{t}^{H} K_{t}^{H}-W_{t}^{H} L_{t}^{H}$, subject to the technological constraint (5).

Symmetrically, the representative foreign intermediate goods-producing firm uses $K_{t}^{F}$ units of capital and $L_{t}^{F}$ units of labor to produce $Y_{t}^{B}$ units of a second internationally-traded intermediate good that sells in both countries at the common price $P_{t}^{B}$. The firm operates with a technology of the same Cobb-Douglas form described in (5), but which gets hit by the foreign neutral productivity shock $Z_{t}^{F}$; the firm acts to maximize its profits, measured likewise as revenues minus costs.

\subsection{Final Goods-Producing Firms}

The representative domestic final goods-producing firm uses $A_{t}^{H}$ units of the home intermediate good and $B_{t}^{H}$ units of the foreign intermediate good to produce $\tilde{C}_{t}^{H}$ units of the home consumption good and $\tilde{I}_{t}^{H}$ units of the home investment good according to the technology described by

$$
\left[(1-\omega)^{1 / \theta}\left(A_{t}^{H}\right)^{(\theta-1) / \theta}+\omega^{1 / \theta}\left(B_{t}^{H}\right)^{(1-\theta) / \theta}\right]^{\theta /(1-\theta)} \geq \tilde{C}_{t}^{H}+\left(1 / V_{t}^{H}\right) \tilde{I}_{t}^{H}
$$

where the term $1 / V_{t}^{H}$ out in front of investment $\tilde{I}_{t}^{H}$ on the right-hand side of (6) captures the effects of stochastic, investment-specific technological change of the kind described in a closed economy by Greenwood, Hercowitz, and Huffman (1988) and Greenwood, Hercowitz, and Krusell (1997) and introduced into small-open-economy or two-country models by Finn (1999), Boileau (2002), Letendre and Luo (2007), Raffo (2009), Coeurdacier, Kollmann, and Martin (2010), and Mandelman, Rabanal, Rubio-Ramirez, and Vilan (2010). The positive parameter $\theta$ measure the elasticity of substitution between the two intermediate goods in producing the final goods; the share parameter $\omega$ lies between zero and one. 
The firm chooses $\tilde{C}_{t}^{H}, \tilde{I}_{t}^{H}, A_{t}^{H}$, and $B_{t}^{H}$ at each date $t=0,1,2, \ldots$ to maximize its profits, $P_{t}^{H} \tilde{C}_{t}^{H}+$ $X_{t}^{H} \tilde{I}_{t}^{H}-P_{t}^{A} A_{t}^{H}-P_{t}^{B} B_{t}^{H}$, subject to the technological constraint (6). The solution to this problem requires that

$$
X_{t}^{H} / P_{t}^{H}=1 / V_{t}^{H}
$$

hold in any equilibrium in which both consumption and investment goods get produced in the home country, confirming that Greenwood, Hercowitz, and Krusell's (1997) insight that investmentspecific technological progress manifests itself partly in a falling price of investment relative to consumption goods applies in this model as well.

The representative foreign final goods-producing firm uses $A_{t}^{F}$ units of the home intermediate good and $B_{t}^{F}$ units of the foreign intermediate good to produce $\tilde{C}_{t}^{F}$ units of the foreign consumption good and $\tilde{I}_{t}^{F}$ units of the foreign investment good according to a constant-elasticity-of-substitution production function that is symmetric to the one shown in (6). The same argument used above to derive (7) implies that, in equilibrium, the relative price $X_{t}^{F} / P_{t}^{F}$ of investment to consumption in the foreign country is inversely related to the foreign investment-specific technology shock $V_{t}^{F}$.

\subsection{Governments}

Both governments run balanced budgets, according to which lump-sum taxes raised from con-

sumers are used to fund purchases of the local consumption good; hence, $T_{t}^{H} / P_{t}^{H}=G_{t}^{H}$ and $T_{t}^{F} / P_{t}^{F}=G_{t}^{F}$ for all $t=0,1,2, \ldots$ Stochastic fluctuations in the home and foreign government spending variables $G_{t}^{H}$ and $G_{t}^{F}$, as described below, provide an additional source of volatility in output and employment beyond the two types of technology shocks.

\subsection{Equilibrium Conditions}

Keeping in mind that the two intermediate goods are traded internationally and that the bond holding costs, labor adjustment costs, and government purchases are all measured in units of the local 
consumption goods, the model's market clearing conditions are $Y_{t}^{A}=A_{t}^{H}+A_{t}^{F}, Y_{t}^{B}=B_{t}^{H}+B_{t}^{F}$,

$$
\begin{aligned}
& \tilde{C}_{t}^{H}=C_{t}^{H}+\left(\frac{\phi_{d}}{2}\right) U_{t}^{H}\left(\frac{D_{t+1}^{H}}{U_{t}^{H}}\right)^{2}+\left(\frac{\phi_{l}}{2}\right) U_{t-1}^{H}\left(\frac{L_{t}^{H}}{L_{t-1}^{H}}-1\right)^{2} L_{t-1}^{H}+G_{t}^{H}, \\
& \tilde{C}_{t}^{F}=C_{t}^{F}+\left(\frac{\phi_{d}}{2}\right) U_{t}^{F}\left(\frac{D_{t+1}^{F}}{U_{t}^{F}}\right)^{2}+\left(\frac{\phi_{l}}{2}\right) U_{t-1}^{F}\left(\frac{L_{t}^{F}}{L_{t-1}^{F}}-1\right)^{2} L_{t-1}^{F}+G_{t}^{F}
\end{aligned}
$$

$\tilde{I}_{t}^{H}=I_{t}^{H}, \tilde{I}_{t}^{F}=I_{t}^{F}$, and $D_{t}^{H}+D_{t}^{F}=0$ for all $t=0,1,2, \ldots$ in the model with stationary preference shocks. In the model with nonstationary preference shocks, (8) and (9) must be modified, replacing the labor adjustment cost specification from (2) with the alternative form shown in (3).

\subsection{Exogenous Shocks}

In addition, the model's equilibrium conditions include laws of motion for the eight exogenous shocks: the preference shock, the neutral technology shock, the investment-specific technology shock, and the government spending shock in each of the two countries.

Following Rabanal, Rubio-Ramirez, and Tuesta (2009), the neutral and investment-specific technology shocks are assumed to be nonstationary but cointegrated, so that

$$
\begin{aligned}
& \ln \left(Z_{t}^{H} / Z_{t-1}^{H}\right)=\left(1-\rho_{z}^{H}\right) \ln (z)+\rho_{z}^{H} \ln \left(Z_{t-1}^{H} / Z_{t-2}^{H}\right)+\kappa_{z}^{H}\left[\ln \left(Z_{t-1}^{F}\right)-\ln \left(Z_{t-1}^{H}\right)\right]+\varepsilon_{z t}^{H}, \\
& \ln \left(Z_{t}^{F} / Z_{t-1}^{F}\right)=\left(1-\rho_{z}^{F}\right) \ln (z)+\rho_{z}^{F} \ln \left(Z_{t-1}^{F} / Z_{t-2}^{F}\right)+\kappa_{z}^{F}\left[\ln \left(Z_{t-1}^{H}\right)-\ln \left(Z_{t-1}^{F}\right)\right]+\varepsilon_{z t}^{F}, \\
& \ln \left(V_{t}^{H} / V_{t-1}^{H}\right)=\left(1-\rho_{v}^{H}\right) \ln (v)+\rho_{v}^{H} \ln \left(V_{t-1}^{H} / V_{t-2}^{H}\right)+\kappa_{v}^{H}\left[\ln \left(V_{t-1}^{F}\right)-\ln \left(V_{t-1}^{H}\right)\right]+\varepsilon_{v t}^{H},
\end{aligned}
$$

and

$$
\ln \left(V_{t}^{F} / V_{t-1}^{F}\right)=\left(1-\rho_{v}^{F}\right) \ln (v)+\rho_{v}^{F} \ln \left(V_{t-1}^{F} / V_{t-2}^{F}\right)+\kappa_{v}^{F}\left[\ln \left(V_{t-1}^{H}\right)-\ln \left(V_{t-1}^{F}\right)\right]+\varepsilon_{v t}^{F}
$$

for all $t=0,1,2, \ldots$ In (10)-(13), $z$ and $v$ are positive parameters governing the long-run average rates of neutral and investment-specific technological progress in both countries along the model's steady-state growth path, $\rho_{z}^{H}, \rho_{z}^{F}, \rho_{v}^{H}$, and $\rho_{v}^{F}$, all lying between zero and one, are parameters 
governing the persistence of movements in the growth rates of the neutral and investment-specific technology shocks, $\kappa_{z}^{H}, \kappa_{z}^{F}, \kappa_{v}^{H}$, and $\kappa_{v}^{F}$ are nonnegative error-correction parameters governing the speed of technological convergence across the two economies, and $\varepsilon_{z t}^{H}, \varepsilon_{z t}^{F}, \varepsilon_{v t}^{H}$, and $\varepsilon_{v t}^{F}$ are mutually and serially uncorrelated innovations that are normally distributed with zero means and standard deviations $\sigma_{z}^{H}, \sigma_{z}^{F}, \sigma_{v}^{H}$, and $\sigma_{v}^{F}$.

Since this specification allows for serial correlation in the growth rates of both country-specific technology shocks, it can account for the highly persistent differences in real consumption and investment growth both within and across economies displayed for the US and EA in figure 1. Meanwhile, the assumptions, implicit in (10)-(13), that the neutral and investment-specific shocks are cointegrated and have the same long-run average growth rates across countries, imply that over very long periods of time, productivity levels and growth rates converge across countries: these restrictions get enforced when at least one in each pair, $\kappa_{z}^{H}$ and $\kappa_{z}^{F}$ for the neutral shocks and $\kappa_{v}^{H}$ and $\kappa_{v}^{F}$ for the investment-specific shocks, is strictly positive. Finally, when $v>1$, so that there is a nonzero average growth rate of the investment-specific technology shock, a common, downward trend in the price of investment appears in both countries and real investment will tend to grow faster than real consumption in both countries over time; again, these dynamics generalize those studied in a closed economy setting by Greenwood, Hercowitz, and Krusell (1997).

Following Chang, Doh, and Schorfheide (2007), two alternative specifications for the preference shocks are considered. The first specification assumes that the preference shock in each country follows a stationary autoregressive process, so that

$$
\ln \left(M_{t}^{H}\right)=\left(1-\rho_{m}^{H}\right) \ln \left(m^{H}\right)+\rho_{m}^{H} \ln \left(M_{t-1}^{H}\right)+\varepsilon_{m t}^{H}
$$

and

$$
\ln \left(M_{t}^{F}\right)=\left(1-\rho_{m}^{F}\right) \ln \left(m^{F}\right)+\rho_{m}^{F} \ln \left(M_{t-1}^{F}\right)+\varepsilon_{m t}^{F}
$$

for all $t=0,1,2, \ldots$, where the positive parameters $m^{H}$ and $m^{F}$ determine the steady-state values of the shocks, the persistence parameters $\rho_{m}^{H}$ and $\rho_{m}^{F}$ both lie between zero and one, and the 
innovations $\varepsilon_{m t}^{H}$ and $\varepsilon_{m t}^{F}$ are mutually and serially uncorrelated with zero means and standard deviations $\sigma_{m}^{H}$ and $\sigma_{m}^{F}$. The second specification assumes instead that the two preference shocks are nonstationary but cointegrated, so that

$$
\ln \left(M_{t}^{H} / M_{t-1}^{H}\right)=\left(1-\rho_{m}^{H}\right) \ln (m)+\rho_{m}^{H} \ln \left(M_{t-1}^{H} / M_{t-2}^{H}\right)+\kappa_{m}^{H}\left[\ln \left(M_{t-1}^{F}\right)-\ln \left(M_{t-1}^{H}\right)\right]+\varepsilon_{m t}^{H}
$$

and

$$
\ln \left(M_{t}^{F} / M_{t-1}^{F}\right)=\left(1-\rho_{m}^{F}\right) \ln (m)+\rho_{m}^{F} \ln \left(M_{t-1}^{F} / M_{t-2}^{F}\right)+\kappa_{m}^{F}\left[\ln \left(M_{t-1}^{H}\right)-\ln \left(M_{t-1}^{F}\right)\right]+\varepsilon_{m t}^{F}
$$

for all $t=0,1,2, \ldots$, where the positive parameter $m$ determines the common long-run growth rate of the preference shocks in the two countries, the parameters $\rho_{m}^{H}$ and $\rho_{m}^{F}$, now governing the persistence of movements in the growth rates of the preference shocks, both lie between zero and one, and the innovations $\varepsilon_{m t}^{H}$ and $\varepsilon_{m t}^{F}$ are again mutually and serially uncorrelated with zero means and standard deviations $\sigma_{m}^{H}$ and $\sigma_{m}^{F}$.

Finally, so that the levels of government spending in the two economies increase as those economies experience stochastic long-run growth, it is assumed that fiscal policies give rise to random fluctuations in $g_{t}^{H}=G_{t}^{H} / U_{t}^{H}$ and $g_{t}^{F}=G_{t}^{F} / U_{t}^{F}$; the government spending variables therefore get scaled by the same growth factors that keep the adjustment cost specifications consistent with long-run balanced growth. In particular, these scaled government spending variables are assumed to follow the stationary autoregressive processes

$$
\ln \left(g_{t}^{H}\right)=\left(1-\rho_{g}^{H}\right) \ln \left(g^{H}\right)+\rho_{g}^{H} \ln \left(g_{t-1}^{H}\right)+\varepsilon_{g t}^{H}
$$

and

$$
\ln \left(g_{t}^{F}\right)=\left(1-\rho_{g}^{F}\right) \ln \left(g^{F}\right)+\rho_{g}^{F} \ln \left(g_{t-1}^{F}\right)+\varepsilon_{g t}^{F}
$$

for all $t=0,1,2, \ldots$, where the positive parameters $g^{H}$ and $g^{F}$ pin down the average ratios of government spending to private consumption in the two economies, the persistence parameters $\rho_{g}^{H}$ 
and $\rho_{g}^{F}$ both lie between zero and one, and the innovations $\varepsilon_{g t}^{H}$ and $\varepsilon_{g t}^{F}$ are mutually and serially uncorrelated with zero means and standard deviations $\sigma_{g}^{H}$ and $\sigma_{g}^{F}$.

\subsection{Equilibrium System}

The first-order conditions describing private agents' optimizing behavior, the market clearing conditions, and the laws of motion describing the stochastic evolution of the exogenous shocks form a system of equations that determines the equilibrium behavior of the model's endogenous variables. This system implies that in each country, real consumption and investment inherit distinct stochastic trends from the nonstationary neutral and investment-specific technology shocks and, in the specification with nonstationary preference shocks, the preference shocks as well. Since the nonstationary shocks are cointegrated across countries, however, home and foreign consumption and home and foreign investment form pairs of cointegrated variables, and regardless of the stationarity properties of the preference shocks, the scaling of the government spending variables introduced in (18) and (19) implies that government spending and consumption are cointegrated within each country. Hours worked, too, inherit their own stochastic trend but are cointegrated across countries in the model with nonstationary preference shocks.

Hence, the model with stationary preference shocks has implications for eight observable, stationary variables: the growth rate $g_{t}^{C H}=C_{t}^{H} / C_{t-1}^{H}$ of home consumption, the growth rate $g_{t}^{I H}=$ $I_{t}^{H} / I_{t-1}^{H}$ of home investment, the ratio $r_{t}^{G C H}=G_{t}^{H} / C_{t}^{H}$ of government spending to consumption in the home country, hours worked $L_{t}^{H}$ in the home country, the ratio $r_{t}^{C F H}=C_{t}^{F} / C_{t}^{H}$ of foreign to home consumption, the ratio $r_{t}^{I F H}=I_{t}^{F} / I_{t}^{H}$ of foreign to home investment, the ratio $r_{t}^{G C F}=G_{t}^{F} / C_{t}^{F}$ of government spending to consumption in the foreign country, and hours worked $L_{t}^{F}$ in the foreign country. The model with nonstationary preference shocks has implications for the same eight observables, except that the hours worked variables $L_{t}^{H}$ and $L_{t}^{F}$ must be replaced by their stationary counterparts: the growth rate $g_{t}^{L H}=L_{t}^{H} / L_{t-1}^{H}$ in the home country and the ratio $r_{t}^{L F H}=L_{t}^{F} / L_{t}^{H}$ of foreign to home hours worked. When the equilibrium system is rewritten in terms of these stationary variables, it implies that in the absence of shocks, the global economy converges to a 
steady-state growth path along which each stationary variable is constant. The system can therefore be log-linearized around its steady state to form a set of linear expectational difference equations that can be solved using methods outlined, for example, by Klein (2000).

Conveniently, the approximate solution obtained in this way takes the form of a state-space econometric model, linking the eight observable variables listed above to an unobservable state vector that includes stationary transformations of the model's eight shocks. Hence, under the additional assumption that the innovations to the eight shocks are normally distributed, Kalman filtering algorithms described, for instance, by Hamilton (1994, Ch.13) can be used to estimate the model's structural parameters via maximum likelihood and to make inferences about the realizations of the unobservable shocks based on information contained in the observable data.

\section{Empirical Strategy and Results}

The empirical model has a large number of parameters, making it desirable to calibrate at least some of them, especially those for which a wide consensus on reasonable values exists; the estimation exercise can then focus all of its power on the remaining parameters, in particular those describing the magnitudes of the labor and capital adjustment costs and, especially, the stochastic processes for the various shocks, about which much less in known. For instance, Backus, Kehoe, and Kydland (1994), Heathcote and Perri (2002), and Rabanal, Rubio-Ramirez, and Tuesta (2009) all work with calibrated two-country models that set the discount factor $\beta=0.99$, consumption's share parameter $\mu=0.34$, the risk aversion coefficient $\gamma=2$, the quarterly depreciation rate $\delta=0.025$, and capital's share $\alpha=0.36$. These same parameter settings are also used here. The parameters $\eta^{H}$ and $\eta^{F}$ are then set equal to the constant ratio of investment to capital in each country so that, as noted above, the levels of the capital adjustment costs equal zero along the model's steady-state growth path. Meanwhile, as also noted above, the small but positive setting $\phi_{d}=0.001$ guarantees that the model's steady-state growth path is unique.

More controversy surrounds the settings for the trade parameters: the share parameter $\omega$ and, to 
an even greater extent, the elasticity of substitution $\theta$ between home and foreign intermediate goods in producing the final goods. Backus, Kehoe, and Kydland (1994) propose the values $\omega=0.15$ and $\theta=1.5$. Heathcote and Perri (2002) continue to use $\omega=0.15$, but select a lower value of $\theta=0.9$. Raffo (2009) also sets $\omega=0.15$, but takes $\theta=0.5$ as a benchmark. And Rabanal, RubioRamirez, and Tuesta (2009) use $\omega=0.10$ and study versions of their model with $\theta=0.85$ and $\theta=0.62$. Much of the disagreement on appropriate values for $\theta$ reflects findings from recent work by Corsetti, Dedola, and Leduc (2008) that emphasize the importance of this parameter in determining the response of international variables to technology shocks. Here, therefore, the analysis follows but broadens the strategy from Rabanal, Rubio-Ramirez, and Tuesta (2009) by fixing $\omega=0.10$ but then leaving $\theta$ as one of the parameters to be estimated instead of calibrated.

In the model with stationary preference shocks, the steady-state growth rates of real consumption and investment in both countries get determined by the steady-state values of $g_{t}^{C H}=v^{\alpha /(1-\alpha)} z$ and $g_{t}^{I H}=v^{1 /(1-\alpha)} z$. In the model with nonstationary preference shocks, the steady-state growth rates of hours worked, real consumption, and real investment in both countries get determined by the steady-state values of $g_{t}^{L H}=m, g_{t}^{C H}=m v^{\alpha /(1-\alpha)} z$ and $g_{t}^{I H}=m v^{1 /(1-\alpha)} z$. Hence, calibrated values for the parameters $z, v$, and $m$ in (10)-(13), (16), and (17) can be selected so that these steady-state growth rates match the average growth rates of hours, consumption, and investment in the data. In particular, using the quarterly series, 1970:1-2007:4, described in the appendix, the average annual growth rate of real, per-capita consumption works out to be 1.83 percent for the US, 1.72 percent for the EA, and hence 1.78 percent for the two economies combined. Similarly, the average annual growth rate of real, per-capita investment equals 2.36 percent for the US, 1.51 percent for the EA, and hence 1.94 percent for the two countries combined, while the average annual growth rate of per-capita hours worked is -0.14 percent for the US, -0.09 percent for the EA, and hence -0.12 percent for the two economies combined. Converting these net, annual figures from the data into gross, quarterly rates of change as in the model and using the value of $\alpha=0.36$ selected previously leads to the settings $z=1.0042$ and $v=1.0004$ for the model with stationary preference shocks and $m=0.9997, z=1.0045$, and $v=1.0004$ for the model with nonstationary 
preference shocks.

Finally, for the model with stationary preference shocks, the settings $m^{H}=m^{F}=0.9$ for the constants in (14) and (15) imply that the representative consumers in both economies spend $1 / 3$ of their time working along the steady-state growth path, matching an assumption that is made commonly in the real business cycle literature. And in both model variants, the settings $g^{H}=g^{F}=$ 0.20 in (18) and (19) imply a steady-state ratio of real government spending to real consumption of about 30 percent in both economies, roughly matching the facts that in the sample of data themselves, government spending has averaged 31 percent of private consumption in the US and 34 percent of private consumption in the EA.

Table 1 reports estimates of the model's remaining parameters, numbering 23 for the model with stationary preference shocks and 25 for the model with nonstationary preference shocks, obtained via maximum likelihood using quarterly readings, 1970:1-2007:4, on the sets of eight observables selected above to reflect the multiple stochastic trends that appear in and are shared by those variables in theory. Since the calibrated parameters selected above suffice to pin down the steady-state values of the model's stationary variables, each of the eight series is demeaned prior to estimation; thus, identification of the estimated parameters comes from the dynamics implied by the model and seen in the data. The standard errors, also reported in table 1, are derived from a bootstrapping procedure described by Efron and Tibshirani (1993, Ch.6), according to which the model, with its parameters fixed at their estimated values, gets used to generate 1000 samples of data on the same series found in the actual US and EA data. These artificial series then get used to re-estimate the model's parameters 1000 times, and the standard errors get computed as the standard deviations of the parameter estimates taken across those 1000 replications. Conveniently and by construction, therefore, this bootstrapping procedure accounts for the finite-sample properties of the maximum likelihood estimates as well as the constraints, requiring some parameters to be nonnegative and others to lie between zero and one, that are imposed during estimation.

For both versions of the model, with stationary and nonstationary preference shocks, the estimate of the elasticity parameter $\theta$ comes in around 1.5 , above several others found in the recent 
literature, including Lubik and Schorfheide's (2005) 0.43, Rabanal and Tuesta's (2010) 0.94, and Bergin's (2006) 1.13. Each of these previous studies, however, works with a New Keynesian DSGE model and therefore uses data on nominal as well as real variables in the estimation. Here, where the focus remains exclusively on real variables, it is perhaps not surprising that the estimates of $\theta$ gravitative back towards the value originally proposed by Backus, Kehoe, and Kydland (1994) in the calibration of their international real business cycle model. The estimates of the labor adjustment cost parameter $\phi_{l}$ appear significant, both economically and statistically, confirming Chang, Doh, and Schorfheide's (2007) finding that these costs become important in models with persistent preference shocks; the estimates of the capital adjustment cost parameter $\phi_{k}$ are smaller but significant as well.

Most interestingly, the estimates of the error-correction parameters display a highly consistent pattern, with those for the US coming in positive but those for the EA always lying up against their lower bound of zero. Also noteworthy, while both US and EA neutral technology shocks and the US investment-specific technology shock are estimated to have growth rates with only modest amounts of persistence, the EA investment-specific shock, though much less volatile than all of the other disturbances on a quarter-to-quarter basis given the very small estimates of the standard deviation $\sigma_{v}^{F}$ of its innovation, appears to be extremely persistent, with estimates of $\rho_{v}^{F}$ above 0.95 for both versions of the model. All these properties of the estimates get reflected in figure 2 , which plot impulse responses of the neutral and investment-specific productivity levels $Z_{t}^{H}, Z_{t}^{F}$, $V_{t}^{H}$, and $V_{t}^{F}$ to innovations to each of these four shocks; the graph shows results for the model with stationary preference shocks but, given the stability of the parameter estimates across the two model variants, they look much the same for the model with nonstationary preference shocks. In particular, the figure highlights how the patterns in the estimated error-correction coefficients imply that neutral and investment-specific shocks originating in the EA gradually diffuse to affect the US as well, while the same disturbances hitting the US leave EA productivity unchanged. The figure also reinforces how much more persistent the EA investment-specific technology shock is compared to all of the other disturbances. 
These same properties of the maximum likelihood estimates get reflected in the graphs shown in the top two rows of figure 2, which illustrate most directly the model's interpretation of the data by plotting out model-based estimates of the historical paths of the productivity variables $Z_{t}^{H}, Z_{t}^{F}, V_{t}^{H}$, and $V_{t}^{F}$. These estimates are constructed on the basis of full-sample information using the Kalman smoothing algorithms described by Hamilton (1994, Ch.13) and generalized by Kohn and Ansley (1983) to deal with cases like this one, where the presence of lagged variables in the state vector implies that the covariance matrix of one-step-ahead forecast errors for the state becomes singular. Once again the results do not depend sensitively on the specification, stationary or nonstationary, for the preference shocks. The solid lines in these graphs confirm that the broad characterization of post-World War II US macroeconomic history provided by Ireland and Schuh's (2008) closed-economy analysis is robust to the consideration of international data. In particular, the figure suggests that the productivity slowdown experienced in the US during the 1970s reflects, above all else, a complete lack of neutral technological progress over a period that extends from the beginning of the sample in 1970 through the early 1980s. Meanwhile, the more recent productivity revival that accompanied the long economic expansion of the 1990s in the US gets attributed to rapid investment-specific technological change that, in retrospect, appears more like a one-time permanent shift in the level of $V_{t}^{H}$ than a persistent change in the growth rate of $V_{t}^{H}$.

The dashed lines in figure 2, however, tell a very different story for postwar Europe. According to the graphs, neutral productivity growth continued at a normal pace in Europe during the 1970s, even as it was stalled out in the US. Instead, Europe's productivity problems appear concentrated in the investment-specific sector, with the EA apparently experiencing no spillovers, positive or negative, from the US, even during the boom of the 1990s. Overall, the maximum likelihood estimates of the parameters, the impulse responses, and the smoothed estimates of the shocks point to the broader conclusion that over the decades since 1970, the EA economy has remained insulated against a variety of technological disturbances - both neutral and investment-specific, both favorable and adverse - experienced in the US.

The graphs in the bottom row of figure 2 present alternative estimates of neutral and investment- 
specific technological change in the US and EA that come from more conventional growth accounting exercises. As described in more detail in the appendix, the same data for investment used to estimate the model are cumulated to form series for the capital stock in each economy; these series, in turn, are combined with the same data on labor inputs used to estimate the model and new data on real GDP to back out series for neutral productivity levels for each economy using aggregate production functions of the same Cobb-Douglas form shown above in (5). Meanwhile, following Greenwood, Hercowitz, and Krusell (1997) and as suggested by (7), the series for investmentspecific productivity are constructed using data on the relative price of investment to consumption. Thus, these alternative estimates impose some, but not all, of the theoretical restrictions implied by the DSGE model, yet also exploit additional data on real GDP and relative prices not used before.

Broadly speaking, these growth accounting exercises lead to conclusions similar to those coming from the estimated DSGE model: in the bottom panels of figure 2, neutral technological progress continues throughout the 1970s in the EA even as it stagnates in the US, but the EA also largely misses out on the more rapid investment-specific technological progress experienced in the US during the 1990s. On the other hand, the measures of investment-specific technological change implied by the estimated model do look different from those coming off the growth accounting exercise, particularly for the US case, where the model-based estimates exhibit considerably more high-frequency volatility. This last result echoes findings obtained for the US as a closed economy presented and discussed by Justiniano, Primiceri, and Tambalotti (2009) and Schmitt-Grohe and Uribe (2009), suggesting that the investment-specific technology shocks identified by the twocountry model used here may reflect stochastic variations in, for example, financial-sector frictions that affect the productivity of newly-installed physical capital as well as purely technological improvements in those same capital goods.

Finally, as another set of checks on the estimated model, table 2 compares statistics describing the volatilities of and co-movements between key macroeconomic variables in the US and EA data to the same statistics as implied by the model, following the traditional approach used in the real business cycle literature that passes all series, in natural logarithms, through the Hodrick- 
Prescott (1997) filter to isolate movements at business cycle frequencies. The table confirms that the stochastic growth model estimated here shares many of the same strengths and weaknesses as other international real business cycle models. Panels A and B show that both model variants do an adequate job of matching the business-cycle volatilities of real GDP, consumption, investment, and hours worked, although government spending in the models moves too much at business cycle frequencies when compared to the data. In addition, panel $\mathrm{C}$ shows that the model with stationary preference shocks can account for a key feature of the data that Backus, Kehoe, and Kydland's (1994) original specification cannot: that cross-country correlations in outputs exceed those in consumptions. On the other hand, both versions of the estimated model fail to reproduce the positive cross-country correlation in investments seen in the data, grossly underpredict the volatility in the real exchange rate, computed in the model as $R E R_{t}=P_{t}^{F} / P_{t}^{H}$, and fail to solve the puzzle first identified by Backus and Smith (1993), that the ratio of consumptions across countries is negatively correlated with the real exchange rate in the data but positively correlated with the real exchange rate in the model. These last results echo those discussed in much more detail by Mandelman, Rabanal, Rubio-Ramirez, and Vilan (2010), who also work with an international real business cycle model featuring nonstationary but cointegrated investment-specific technology shocks.

\section{Conclusion}

Macroeconomic data from the United States and Euro Area economies often behave quite differently, even when summarized in terms of their most basic properties. Perhaps most significantly, while over much of the post-World War II period real investment has grown faster than real consumption in the US, exactly the opposite turns out to be true for the EA.

This paper interprets these differential trends using a two-country stochastic growth model that uses nonstationary but cointegrated neutral and investment-specific technology shocks to formalize the idea that while productivity levels may converge across economies in the very long run, there can also be highly persistent departures from the steady-state growth path lasting for decades or 
more. When estimated with US and EA data on real consumption, investment, government spending, and hours worked, using an empirical strategy that exploits the fact that these data contain, and to some extent share, multiple stochastic trends, this model confirms the popular suspicion that the EA largely missed out on the rapid investment-specific technological change that fueled the extended boom in the US economy during the 1990s. On the other hand, the estimated model also suggests that neutral technological progress continued at a relatively healthy pace in the EA during the 1970s, even as the US was experiencing its productivity slowdown. More generally, the estimated model points in various ways to persistent swings in both neutral and investment-specific productivity growth originating in the US but not transmitted to the EA.

As noted above, measures of investment-specific technological change implied by the model, which is estimated using data on macroeconomic quantities alone, appear different and in some ways more volatile than those derived from a more conventional growth accounting exercise based on price data, suggesting that the shocks identified by the model may reflect shifting financialsector frictions unique to each economy as well as purely technological changes. Alternatively, European institutions may have done a better job at stabilizing the EA economy, but at the cost of slowing down technological adoption and stifling technological innovation, at least to some degree. Digging deeper into these, and possibly other, underlying causes for the strikingly different productivity trends uncovered here for the US and EA remains an important task for future research.

\section{Appendix: Data Description and Sources}

All US data come from the Federal Reserve Bank of St Louis' FRED database; and all of the EA data come from the Area Wide Model dataset first assembled by Fagan, Henry, and Mestre (2005) and now made available by the Euro Area Business Cycle Network, except for the population series, which comes from the OECD. In figure 1, the series for US real consumption and investment are those for real personal consumption expenditures and real gross private domestic investment, 
measured in chained 2000 dollars. The series for EA consumption and investment are those for real private consumption and real gross investment, both with base year 1995, from the EU-15.

The same consumption and investment series are used to estimate the model, except that those for the US are converted to per-capita terms by dividing by the civilian noninstitutional population ages 16 and over and those for the EA are converted to per-capita terms by dividing by a measure obtained by aggregating annual figures for national populations, ages 15-64, from 12 of the EA-15 countries (including Austria, Belgium, Finland, France, Germany, Greece, Ireland, Italy, Luxembourg, Netherlands, Portugal, and Spain but excluding Cyprus, Malta, and Slovenia) for which OEDC data are available and using linear interpolation to convert the annual figures into a quarterly series. For the US, the series for government expenditures and hours worked used to estimate the model correspond to real government expenditures, again in chained 2000 dollars, and hours of all persons in the nonfarm business sector, both converted to per-capita terms as just described above. For the EA, the series for government spending used to estimate the model corresponds to real government consumption, again with base year 1995 and again converted to per-capita terms as described above. Since the AWM dataset lacks a series with direct observations on hours worked, the series for total employment, again expressed in per-capital terms using the OECD population figures, must be used instead.

The growth accounting exercises summarized in the bottom row of figure 2 cumulate the series for real investment used to estimate model according to the standard law of motion $K_{t+1}=(1-$ $\delta) K_{t}+I_{t}$, assuming a quarterly depreciation rate of $\delta=0.025$ and an initial ratio of investment to capital in each economy equal to the same steady-state value implied by the DSGE model. Labor inputs are measured by the same series used to estimate the model, and output is measured by real GDP, in chained 2000 dollars for the US and with base year 1995 for the EA. The measures of neutral technological change are obtained with these data, assuming that the aggregate production function is Cobb-Douglas with capital's share $\alpha=0.36$. Meanwhile, the measures of investmentspecific technological change are constructed, as suggested by (7), using the price deflators for investment and consumption to calculate the relative price of investment for each economy. 
The consumption, investment, government spending, and hours worked variables used to compute the summary statistics in table 2 are all the same ones used to estimate the model. The output variables are again measured by real GDP, and all of these series are converted to per-capita terms using the population measures described above. The real exchange rate series is computed by taking the EA harmonized index of consumer prices provided in the AWM dataset, dividing by the US consumer price index for all urban consumers, and dividing again by the nominal euro-per-US dollar exchange rate series provided in the AWM dataset.

Most series from the AWM dataset run from 1970:1 through 2007:4, determining the sample period for the estimation exercise. The nominal euro-per-US dollar exchange rate series begins in 1971:1, however, implying that the real exchange rate data used in table 2 must begin in 1971:1 instead. For the US, all of the series, except for the population data, are seasonally adjusted, and all are available quarterly, except for the monthly population and CPI data, which are converted to quarterly terms through averaging. For the EA, all series, except for the population and nominal exchange rate data, are seasonally adjusted; and all series are quarterly, except for the annual population data which are converted to quarterly terms through interpolation as noted above.

\section{References}

Backus, David K., Patrick J. Kehoe, and Finn E. Kydland, "Dynamics of the Trade Balance and the Terms of Trade: The J-Curve?" American Economic Review 84 (March 1994): 84-103.

Backus, David K. and Gregor W. Smith. "Consumption and Real Exchange Rates in Dynamic Economies with Non-Traded Goods." Journal of International Economics 35 (November 1993): 297-316.

Bergin, Paul R. "How Well Can The New Open Economy Macroeconomics Explain the Exchange Rate and Current Account?" Journal of International Money and Finance 25 (August 2006): 675-701. 
Boileau, Martin. "Trade in Capital Goods and Investment-Specific Technical Change.” Journal of Economic Dynamics and Control 26 (June 2002): 963-984.

Chang, Yongsung, Taeyoung Doh, and Frank Schorfheide. "Non-stationary Hours in a DSGE Model.” Journal of Money, Credit, and Banking 39 (September 2007): 1357-1373.

Coeurdacier, Nicolas, Robert Kollmann, and Philippe Martin. "International Portfolios, Capital Accumulation and Foreign Assets Dynamics." Journal of International Economics 80 (January 2010): 100-112.

Corsetti, Giancarlo, Luca Dedola, and Sylvain Leduc. "International Risk Sharing and the Transmission of Productivity Shocks.” Review of Economic Studies 75 (April 2008): 443-473.

Efron, Bradley and Robert J. Tibshirani. An Introduction to the Bootstrap. Boca Raton: Chapman and Hall/CRC Press, 1993.

Fagan, Gabriel, Jerome Henry, and Ricardo Mestre. "An Area-Wide Model of the Euro-Area." Economic Modelling 22 (January 2005): 39-59.

Finn, Mary G. "An Equilibrium Theory of Nominal and Real Exchange Rate Comovement." Journal of Monetary Economics 44 (December 1999): 430-475.

Fisher, Jonas D.M. “The Dynamic Effects of Neutral and Investment-Specific Technology Shocks.” Journal of Political Economy 114 (June 2006): 413-451.

Greenwood, Jeremy, Zvi Hercowitz, and Gregory W. Huffman. "Investment, Capacity Utilization, and the Real Business Cycle.” American Economic Review 78 (June 1988): 402-417.

Greenwood, Jeremy, Zvi Hercowitz, and Per Krusell. "Long-Run Implications of InvestmentSpecific Technological Change.” American Economic Review 87 (June 1997): 342-362.

Hall, Robert E. "Macroeconomic Fluctuations and the Allocation of Time." Journal of Labor Economics 15 (January 1997, Part 2): S223-S250. 
Hamilton, James D. Time Series Analysis. Princeton: Princeton University Press, 1994.

Heathcote, Jonathan and Fabrizio Perri. "Financial Autarky and International Business Cycles." Journal of Monetary Economics 49 (April 2002): 601-627.

Hodrick, Robert J. and Edward C. Prescott. "Postwar U.S. Business Cycles: An Empirical Investigation.” Journal of Money, Credit, and Banking 29 (February 1997): 1-16.

Ireland, Peter N. and Scott Schuh. "Productivity and US Macroeconomic Performance: Interpreting the Past and Predicting the Future with a Two-Sector Real Business Cycle Model." Review of Economic Dynamics 11 (July 2008): 473-492.

Justiniano, Alejandro, Giorgio E. Primiceri, and Andrea Tambalotti. "Investment Shocks and the Relative Price of Investment." Staff Report 411. New York: Federal Reserve Bank of New York, December 2009.

Kahn, James A. and Robert W. Rich. "Tracking the New Economy: Using Growth Theory to Detect Changes in Trend Productivity." Journal of Monetary Economics 54 (September 2007): 1670-1701.

King, Robert G., Charles I. Plosser, James H. Stock, and Mark W. Watson. "Stochastic Trends and Economic Fluctuations.” American Economic Review 81 (September 1991): 819-840.

Klein, Paul. "Using the Generalized Schur Form to Solve a Multivariate Linear Rational Expectations Model." Journal of Economic Dynamics and Control 24 (September 2000): 1405-1423.

Kohn, Robert and Craig F. Ansley. "Fixed Interval Estimation in State Space Models when Some of the Data are Missing or Aggregated." Biometrika 70 (December 1983): 683-688.

Kydland, Finn E. and Edward C. Prescott. “Time to Build and Aggregate Fluctuations.” Econometrica 50 (November 1982): 1345-1370.

Letendre, Marc-Andre and Daqing Luo. "Investment-Specific Shocks and External Balances in a Small Open Economy Model.” Canadian Journal of Economics 40 (May 2007): 650-678. 
Lubik, Thomas and Frank Schorfheide. "A Baynesian Look at New Open Economy Macroeconomics." NBER Macroeconomics Annual 20 (2005): 313-366.

Mandelman, Federico S., Pau Rabanal, Juan F. Rubio-Ramirez, and Diego Vilan. "Investment Specific Technology Shocks and International Business Cycles: An Empirical Assessment.” Working Paper 2010-3. Atlanta: Federal Reserve Bank of Atlanta, February 2010.

Mulligan, Casey B. “A Century of Labor-Leisure Distortions.” Working Paper 8774. Cambridge: National Bureau of Economic Research, February 2002.

Rabanal, Pau, Juan F. Rubio-Ramirez, and Vicente Tuesta. "Cointegrated TFP Processes and International Business Cycles.” Manuscript. Washington: International Monetary Fund, August 2009.

Rabanal, Pau and Vicente Tuesta. "Euro-Dollar Real Exchange Rate Dynamics in an Estimated Two-Country Model: An Assessment." Journal of Economic Dynamics and Control 34 (April 2010): 780-797.

Raffo, Andrea. "Technology Shocks: Novel Implications for International Business Cycles." Manuscript. Washington: Federal Reserve Board, December 2009.

Sakellaris, Plutarchos and Focco Vijselaar. "Capital Quality Improvement and the Sources of Economic Growth in the Euro Area." Economic Policy 20 (April 2005): 268-306.

Schmitt-Grohe, Stephanie and Martin Uribe. "Closing Small Open Economy Models." Journal of International Economics 61 (October 2003): 163-185.

Schmitt-Grohe, Stephanie and Martin Uribe. "What's News in Business Cycles." Manuscript. New York: Columbia University, March 2009.

Solow, Robert M. "Technical Change and the Aggregate Production Function." Review of Economics and Statistics 39 (August 1957): 312-320. 
Table 1. Maximum Likelihood Estimates and Standard Errors

\begin{tabular}{|c|c|c|c|c|}
\hline \multirow[b]{2}{*}{ Parameter } & \multicolumn{2}{|c|}{ Stationary Preference Shocks } & \multicolumn{2}{|c|}{ Nonstationary Preference Shocks } \\
\hline & Estimate & Standard Error & Estimate & Standard Error \\
\hline$\theta$ & 1.5709 & 0.0467 & 1.4658 & 0.0318 \\
\hline$\phi_{l}$ & 17.1136 & 1.4564 & 2.4080 & 0.3319 \\
\hline$\phi_{k}$ & 2.8582 & 0.5480 & 2.2507 & 0.4191 \\
\hline$\kappa_{m}^{H}$ & - & - & 0.0077 & 0.0029 \\
\hline$\kappa_{m}^{F}$ & - & - & 0.0000 & 0.0006 \\
\hline$\kappa_{z}^{H}$ & 0.0018 & 0.0014 & 0.0021 & 0.0015 \\
\hline$\kappa_{z}^{F}$ & 0.0000 & 0.0006 & 0.0000 & 0.0005 \\
\hline$\kappa_{v}^{H}$ & 0.0090 & 0.0053 & 0.0111 & 0.0043 \\
\hline$\kappa_{v}^{F}$ & 0.0000 & 0.0001 & 0.0000 & 0.0001 \\
\hline$\rho_{m}^{H}$ & 0.9671 & 0.0013 & 0.4870 & 0.0159 \\
\hline$\rho_{m}^{F}$ & 0.9924 & 0.0002 & 0.6456 & 0.0088 \\
\hline$\rho_{z}^{H}$ & 0.1751 & 0.0262 & 0.1519 & 0.0173 \\
\hline$\rho_{z}^{F}$ & 0.3597 & 0.0134 & 0.3835 & 0.0108 \\
\hline$\rho_{v}^{H}$ & 0.1579 & 0.0194 & 0.1491 & 0.0147 \\
\hline$\rho_{v}^{F}$ & 0.9834 & 0.0028 & 0.9682 & 0.0004 \\
\hline$\rho_{g}^{H}$ & 0.9695 & 0.0005 & 0.9648 & 0.0004 \\
\hline$\rho_{g}^{F}$ & 0.9414 & 0.0036 & 0.9608 & 0.0007 \\
\hline$\sigma_{m}^{H}$ & 0.0171 & 0.0011 & 0.0071 & 0.0005 \\
\hline$\sigma_{m}^{F}$ & 0.0064 & 0.0004 & 0.0028 & 0.0002 \\
\hline$\sigma_{z}^{H}$ & 0.0116 & 0.0007 & 0.0120 & 0.0007 \\
\hline$\sigma_{z}^{F}$ & 0.0085 & 0.0005 & 0.0087 & 0.0005 \\
\hline$\sigma_{v}^{H}$ & 0.0156 & 0.0011 & 0.0143 & 0.0010 \\
\hline$\sigma_{v}^{F}$ & 0.0006 & 0.0001 & 0.0006 & 0.0001 \\
\hline$\sigma_{g}^{H}$ & 0.0185 & 0.0009 & 0.0208 & 0.0011 \\
\hline$\sigma_{g}^{F}$ & 0.0098 & 0.0006 & 0.0105 & 0.0006 \\
\hline
\end{tabular}


Table 2. Business Cycle Volatilities and Co-Movements

\begin{tabular}{|c|c|c|c|c|c|}
\hline \multicolumn{6}{|c|}{ A. US Volatilities } \\
\hline & $\operatorname{std}\left(Y^{A}\right)$ & $\operatorname{std}\left(C^{H}\right)$ & $\operatorname{std}\left(I^{H}\right)$ & $\operatorname{std}\left(G^{H}\right)$ & $\operatorname{std}\left(L^{H}\right)$ \\
\hline Data & 1.52 & 1.23 & 7.27 & 1.13 & 1.78 \\
\hline Model with Stationary Preference Shocks & 2.28 & 1.28 & 5.92 & 3.17 & 1.70 \\
\hline Model with Nonstationary Preference Shocks & 1.72 & 1.18 & 5.90 & 3.68 & 1.79 \\
\hline \multicolumn{6}{|c|}{ B. EA Volatilities } \\
\hline & $\operatorname{std}\left(Y^{B}\right)$ & $\operatorname{std}\left(C^{F}\right)$ & $\operatorname{std}\left(I^{F}\right)$ & $\operatorname{std}\left(G^{F}\right)$ & $\operatorname{std}\left(L^{F}\right)$ \\
\hline Data & 1.15 & 0.98 & 2.60 & 0.54 & 0.83 \\
\hline Model with Stationary Preference Shocks & 1.12 & 0.88 & 2.49 & 1.95 & 0.61 \\
\hline Model with Nonstationary Preference Shocks & 1.24 & 0.89 & 2.65 & 2.18 & 0.83 \\
\hline \multicolumn{6}{|c|}{ C. US-EA Volatilities and Co-Movements } \\
\hline & $\operatorname{cor}\left(Y^{A}, Y^{B}\right)$ & $\operatorname{cor}\left(C^{H}, C^{F}\right)$ & $\operatorname{Cor}\left(I^{H}, I^{F}\right)$ & $\operatorname{std}(R E R)$ & $\operatorname{cor}\left(C^{H} / C^{F}, R E R\right)$ \\
\hline Data & 0.50 & 0.39 & 0.31 & 7.43 & -0.22 \\
\hline Model with Stationary Preference Shocks & 0.51 & 0.14 & -0.39 & 0.91 & 0.76 \\
\hline Model with Nonstationary Preference Shocks & -0.03 & 0.13 & -0.39 & 0.88 & 0.78 \\
\hline
\end{tabular}

Notes: Panels A and B compare the percentage standard deviations of US and EA GDPs $Y^{A}$ and $Y^{B}$, consumptions $C^{H}$ and $C^{F}$, investments $I^{H}$ and $I^{F}$, government spendings $G^{H}$ and $G^{F}$, and hours worked $L^{H}$ and $L^{F}$ in the data to the analogous statistics implied by the models with stationary and nonstationary preference shocks. Panel C compares the correlations between US and EA GDPs, consumptions, and investments, the percentage standard deviation of the Euro-Dollar real exchange rate $R E R$, and the correlation between US-EA relative consumptions $C^{H} / C^{F}$ and the real exchange rate in the data to the analogous statistics implied by the models with stationary and nonstationary preference shocks. All series from the data and the model are in natural logarithms and passed through the Hodrick-Prescott (1997) filter with smoothness parameter 1600 to focus on business cycle frequencies. Statistics for the models are computed as averages over 1000 replications, with each individual sample being of the same length as the actual sample of data. 

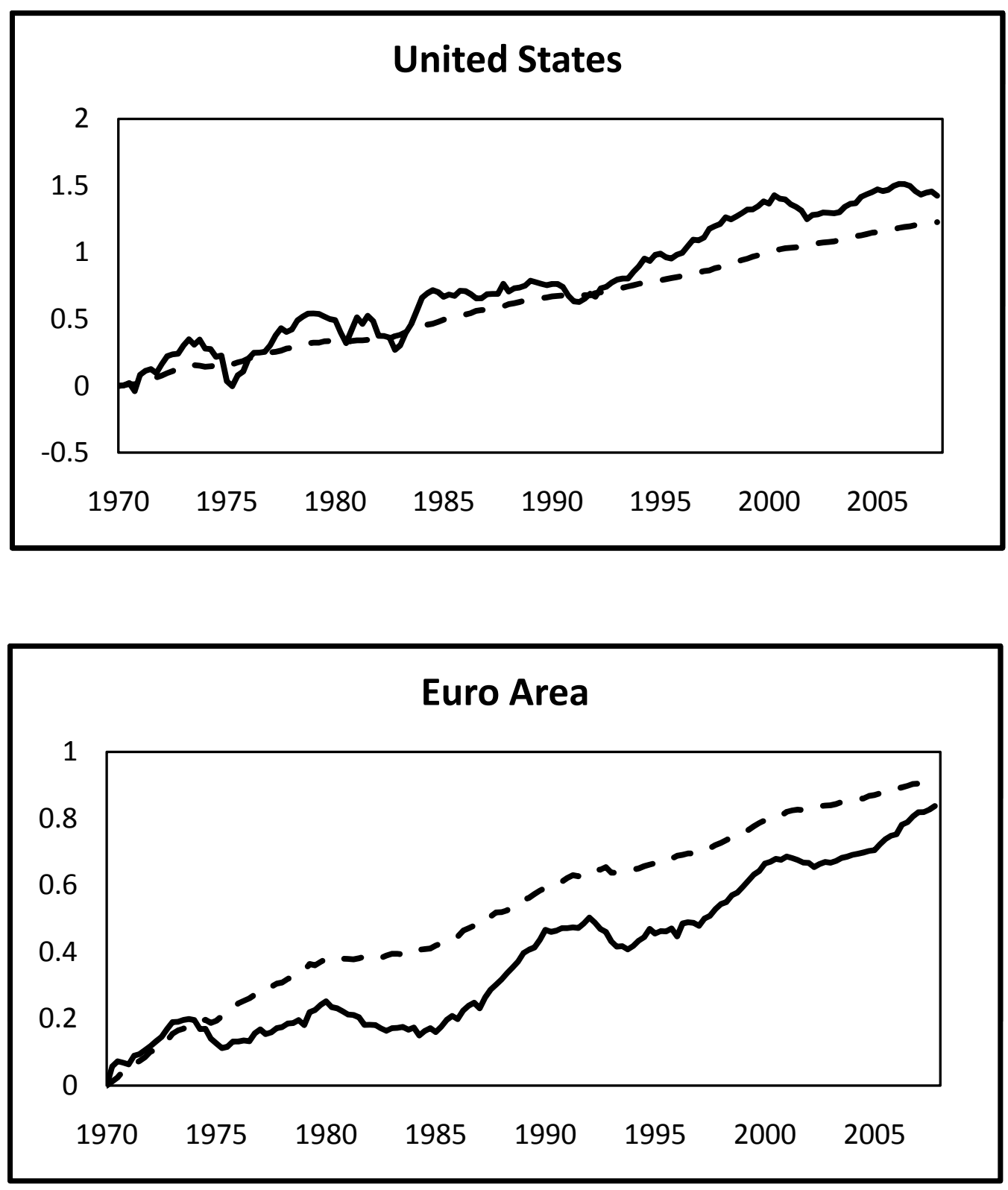

Figure 1. Natural logarithms of real consumption (dashed lines) and investment (solid lines), US and EA, normalized so that $1970=0$ for all series. 

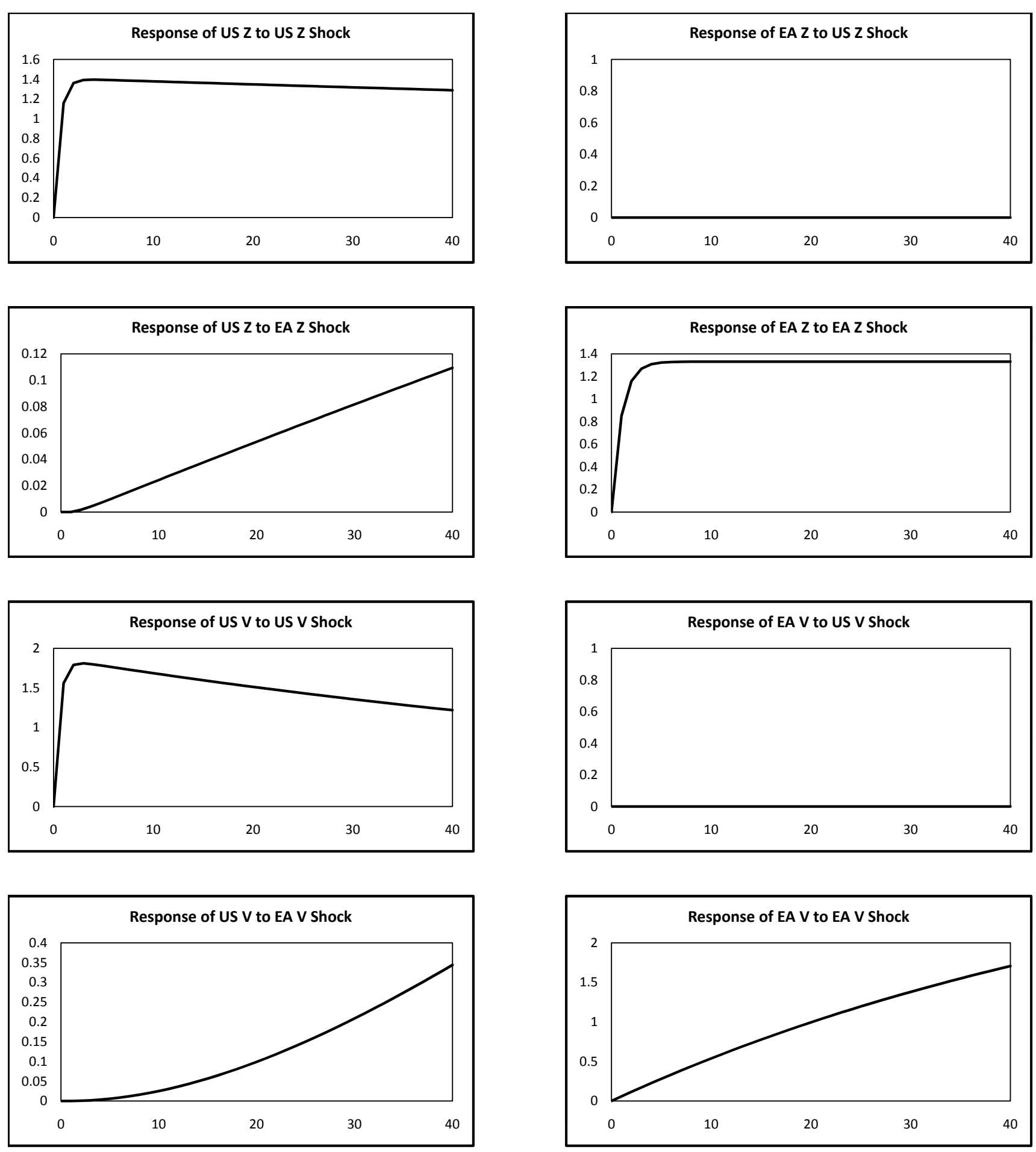

Figure 2. Patterns of Technological Diffusion. Each panel shows the percentage-point response of the neutral (Z) or investment-specific (V) productivity variable in the US or EA to a one-standard-deviation shock to neutral (Z) or investment-specific (V) productivity in the US or EA, as implied by the model with stationary preference shocks. 

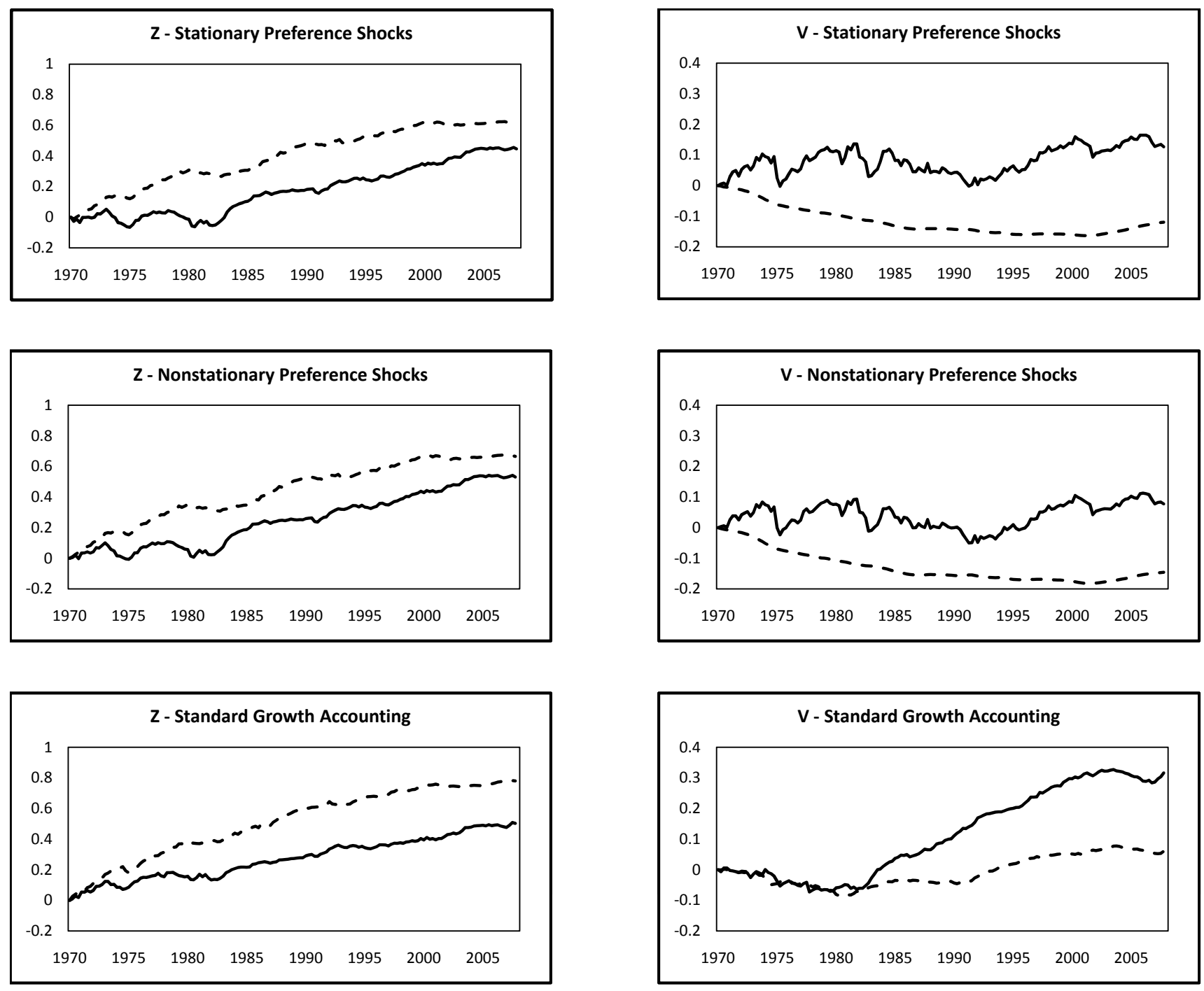

Figure 3. Estimates of neutral ( $\mathrm{Z}$ ) and investment-specific (V) productivity in the US (solid lines) and EA (dashed lines). The top row shows smoothed (full-sample) estimates from the model with stationary preference shocks. The middle row shows smoothed estimates from the model with nonstationary perference shocks. The bottom row shows estimates from a standard growth accounting exercise. 